Noor basha Zeelanbasha

Vellimalai Senthil

Bella Raman Senthil Kumar

https://doi.org/10.21278/TOF.42308

ISSN 1333-1124

eISSN 1849-1391

\title{
AN INTEGRATED APPROACH OF RSM AND MOGA FOR THE PREDICTION OF TEMPERATURE RISE AND SURFACE ROUGHNESS IN THE END MILLING OF AL 6061-T6
}

\begin{abstract}
Cutting temperature, machining parameters, workpiece material, and cutting tool geometry have a significant influence on the achievement of the desired quality of product at a satisfactory cost. The aim of the present study was to develop an empirical model for predicting temperature rise $(T r)$ and surface roughness $(R a)$ in terms of spindle speed $(N)$, feed rate $(F)$, axial depth of cut $\left(D_{a}\right)$, radial depth of cut $\left(D_{r}\right)$, and radial rake angle $(\gamma)$. The experiment was conducted on Al 6061-T6 by using a high-speed steel (HSS) end cutter based on the central composite design of response surface methodology (RSM). A second order mathematical model in terms of machining parameters was developed. The Analysis of Variance (ANOVA) was used to study the performance characteristics in the machining process. The values of Prob $>F$ less than 0.05 indicate that the model terms are significant. The experimental results indicate that the formation of surface defect in the end milling of $\mathrm{Al}$ 6061-T6 results from the re-deposited tool material, plucking, feed marks, micro-pits, and chip layer formation. The high quality of the surface texture is obtained in the combined conditions of high spindle speed, optimal feed rate, lower axial and radial depths of cut, and radial rake angle. Multi objective genetic algorithm (MOGA) has been applied to optimize the machining parameters that simultaneously minimize temperature rise and surface roughness. A set of Pareto-optimal solutions provides flexibility to the manufacturer and the process engineer to select the best setting based on the quality requirements and applications. A verification and validation process shows that the predicted values were found to be in good agreement with the observed values.
\end{abstract}

Key words: $\quad$ End Milling, Machining, MOGA, Prediction, Temperature Rise

\section{Introduction}

Aircraft manufacturers use the 6061-T6 high-strength aluminium alloy to strengthen aluminium aircraft structures. This alloy has the best machinability which results in good surface finish. In the end milling process, heat energy is produced due to friction at the tool chip edge and between the workpiece and the tool. Most of the power used during end milling is converted into heat energy near the cutting edge of the tool. This results in high temperatures in the adjoining and deformation regions of the chip, tool, and workpiece [1]. Temperature rise that inevitably occurs during machining processes causes tool wear, thermal degradation, and expansion of the workpiece, which affects the machining accuracy and quality [2]. Temperature increase in the metal cutting region softens the tool material and wears it out; 
N. Zeelanbasha, V. Senthil, B.R. Senthil Kumar
An Integrated Approach of RSM and MOGA for the Prediction of Temperature Rise and

Surface Roughness in the End Milling of Al 6061-T6

subsequently, the softened tool material disperses into the workpiece material, which causes the surface finish to reduce. Hence, it is important to determine the critical value of the temperature for the reduction of tool wear. Temperature rise on the rake face of the tool affects the surface finish and metallurgical state of the machined surface [3]. El Hakim et al. [4] discussed the heat generated during machining as a cause of difficulties in the machining of alloys. Yong Feng et al. [5] investigated the generation of heat in a workpiece and found that the milling speed and time are responsible for the poor heat conduction between the tool and workpiece. The most commonly adopted method to measure cutting temperatures is to use a thermocouple, a device which measures the average temperature at the tool - workpiece interface [3]. Smart and Trent [6] measured the cutting temperature by introducing a thermocouple into the drilled hole of the workpiece. The values measured by the thermocouple are valuable for studying the effects of the machining parameters (spindle speed $(N)$, feed rate $(F)$, axial depth of cut $\left(D_{r}\right)$, and radial rake angle $(\gamma)$ ) on the temperature and surface finish. A cost-effective application is required for the end milling operation in order to understand the relationship between temperature rise and surface finish. Hence, a most effective model is necessary to predict the cutting temperature. Ali Yildiz [7] suggested that optimization techniques are effective methods for determining the optimal solution to the problem of producing high quality products at lower costs. Bharathi and Baska [8] discussed the methods for the selection of machining parameters in a machining process. Abdalla Alrashdan et al. [9] analysed the most important machining parameters (spindle speed, feed rate, and depth of cut) which affect the machining process. Ahilana and Kumanan [10] conducted experiments based on the central composite design (CCD). Santos et al. [11] developed an effective second order mathematical model for machining parameters (spindle speed, feed rate, and depth of cut). Sivasankar et al. [12] modelled a machining process to map the relationship between the input process parameters and the output response considered in the process. Surface finish is determined by roughness of the machined surface measured using a surface roughness tester; it can be controlled by machining parameters, such as feed rate, spindle speed, and depth of cut [13]. Good surface roughness provides important improvements in the tribological behaviour, fatigue strength, corrosion resistance, and aesthetic appearance of the product [14]. Thanongsak and Tuğrul [15] adopted the response surface methodology (RSM), i.e. statistically based techniques, for modelling and analysis used to find the relationship between the input and output parameters; the authors also investigated the effect of cutting parameters on the surface roughness. Venkata Rao and Murthy [16] adopted the central composite design of response surface method to minimize the number of experiments without reducing the accuracy and, also, to analyse the output responses under the influence of several input factors. Kondayya and Gopala Krishna [17] developed a regression model for the prediction and optimization of machining parameters and response. Senthilkumarl et al. [18] identified the most significant factors by developing regression models. Yuvaraj and Pradeep Kumara [19] suggested that research effort to handle the multi-response characteristic is preferred to the optimization of a single response in order to provide a greater improvement in quality and productivity at a low cost. Konak et al. [20] discussed the genetic algorithm as the most popular heuristic approach to multi-objective design and optimization problems. Sardinas et al. [21] adopted the genetic algorithm optimization technique in order to obtain non-dominated points and to build the Pareto front graph. NSGA-II is an effective multi-response optimization technique used to solve the multi-objective optimization problem and to predict an optimal setting of process parameters for multiple responses [22-23].

In the present study, slotting experiments were conducted on workpieces made of $\mathrm{Al}$ 6061-T6 aluminium alloy. Five parameters, spindle speed $(N)$, feed rate $(F)$, axial depth of cut $\left(D_{a}\right)$, radial depth of cut $\left(\mathrm{D}_{\mathrm{r}}\right)$, and radial rake angle $(\gamma)$ are considered with three different levels based on the suggestion given in $[15,24]$ for the temperature rise $(T r)$ and surface 
roughness $(R a)$. A K-type thermocouple was used to measure the temperature rise in the workpiece, while the surface roughness of the workpiece was measured with a surface tester. RSM is utilized for experimental planning during end milling. Formation of a surface defect on the machined surface texture was analysed using a scanning electron microscope (SEM). Multi- objective optimization using genetic algorithm was performed to find the optimal machining parameters related to a minimum temperature rise and surface roughness. The most important parameters influencing the performance characteristics listed above were investigated using ANOVA.

\section{Experimental methodology and materials}

\subsection{Experimental setup}

The experiments were performed under wet cutting condition on a MAKINO CNC Vertical Machining Centre equipped with a spindle characterized by a speed of $4000 \mathrm{rpm}$ and a maximum torque of $45 \mathrm{~N}-\mathrm{m}$ at $1200 \mathrm{rpm}$, positioning accuracies within $\pm 0.001 \mathrm{~mm}$, and a rapid speed on axis of $5.1 \mathrm{~m} / \mathrm{min}$. The tool used for carrying out the end milling operation was a high speed steel end mill cutter (4 - Flute, 45 degree helix angle) catalogue no F3AH31500AEK45 as recommended by the tool manufacturer (Kenna metal). The workpiece was an aluminium metal matrix (Al 6061-T6) square block with dimensions of $50 \mathrm{~mm} \times 50 \mathrm{~mm} \times 50 \mathrm{~mm}$. The hardness (Brinell) value of $73 \mathrm{BHN}$ was found during the testing under a $500 \mathrm{~g}$ load applied by a10 $\mathrm{mm}$ ball. The chemical composition of Al 6061-T6 is as follows: $\mathrm{Al}$ - $97.5 \mathrm{max}, \mathrm{Si}-0.20$ - 0.60, Fe- $0.35 \max , \mathrm{Cu}-0.1 \mathrm{max}, \mathrm{Mn}-0.1 \mathrm{max}, \mathrm{Mg}$ - 0.45$0.9, \mathrm{Cr}-0.1 \mathrm{max}, \mathrm{Zn}-0.1 \max , \mathrm{Ti}-0.09$. The experimental setup for the workpiece operation is shown in Fig. 1a and $1 b$.

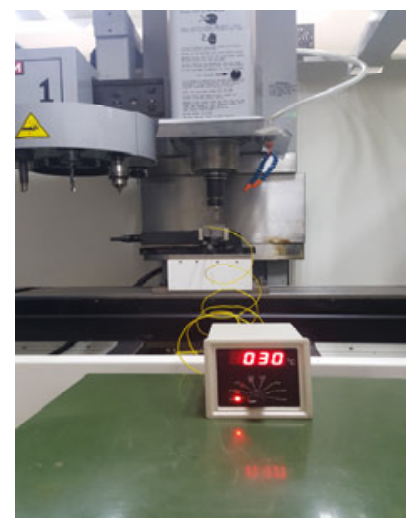

Fig. 1a Measurement of the workpiece temperature $\left(30^{\circ} \mathrm{C}\right)$ before machining

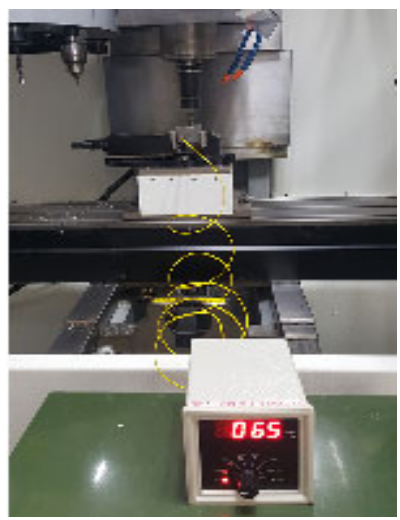

Fig. 1b Maximum temperature of the workpiece $\left(65^{\circ} \mathrm{C}\right)$ measured during machining

\subsection{Experimental Procedures}

In the end milling process, a slotting path of machining operation was made on the workpiece to investigate the temperature rise $(T r)$ and surface roughness $(R a)$. The response variables selected for this study are temperature rise $(T r)$ and surface roughness $(R a)$. During the experiments, temperature rise $(T r)$ was measured by inserting a thermocouple probe into the hole drilled in the workpiece. A digital K-type thermocouple is a type of thermometer used to measure high temperatures. The temperature was measured by using a CRAL model 4172 thermal indicator with a K-type thermocouple measuring a range of up to $1200{ }^{\circ} \mathrm{C}$ with accuracy of $0.1^{\circ} \mathrm{C}$. By using a digital K-type thermocouple, the initial workpiece temperature was noted (shown in Fig 1a), and the maximum temperature was measured during machining 
N. Zeelanbasha, V. Senthil, B.R. Senthil Kumar
An Integrated Approach of RSM and MOGA for the Prediction of Temperature Rise and Surface Roughness in the End Milling of Al 6061-T6

(shown in Fig.1b); the difference between the maximum and the initial temperature gave the temperature rise. The data acquired are noted to obtain the second order mathematical model. Surface roughness $(R a)$ is an important parameter for evaluating the quality of a machining product. In this study, a surface tester, SJ - 210, shown in Figure 1c, was used to measure the machined surface at three different positions; the average surface roughness $(R a)$ is noted in microns. The ranges of machining parameters and the tool radial rake angle were selected from the preliminary research and from the recommendation in the machining data handbook (Hindustan Machine Tools, 2001)

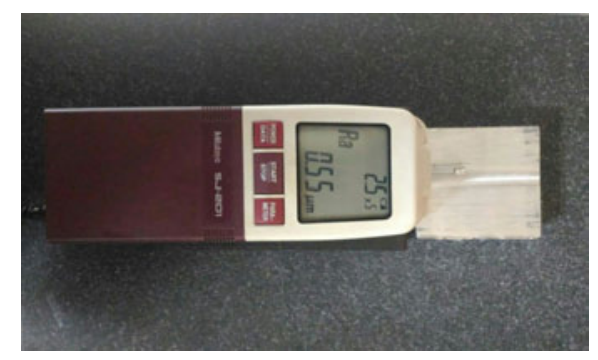

Fig. 1c Surface roughness tester SJ-201

\subsection{Experimental Design}

Response Surface Methodology (RSM) is the most effective method for the analysis of the results obtained from factorial experiments, [19]. It is an effective tool for the modelling and analysis of engineering problems and it also provides more information with a lower number of experiments. The experiments were conducted to identify the temperature rise and surface roughness by considering the machining parameters such as spindle speed, feed rate, axial and radial depths of cut, and radial rake angle; those were optimized using the RSM.

Table 1 Machining and geometrical parameters and their values

\begin{tabular}{|c|l|c|c|c|}
\hline \multirow{2}{*}{$\begin{array}{c}\text { Sl. } \\
\text { No }\end{array}$} & \multirow{2}{*}{$\begin{array}{c}\text { Machining and geometrical } \\
\text { parameters }\end{array}$} & \multicolumn{3}{|c|}{ Factorial Levels } \\
\cline { 3 - 5 } & & -1 & 0 & 1 \\
\hline 1 & Spindle speed $(N)-\mathrm{rpm}$ & 1400 & 2500 & 3600 \\
\hline 2 & Feed rate $(F)-\mathrm{mm} / \mathrm{rev}$ & 0.04 & 0.08 & 0.12 \\
\hline 3 & Axial depth of cut $\left(D_{a}\right)-\mathrm{mm}$ & 0.4 & 0.7 & 1 \\
\hline 4 & ${\text { Radial depth of cut }\left(D_{r}\right)-\mathrm{mm}}^{\circ}$ & 0.4 & 0.7 & 1 \\
\hline 5 & ${\text { Radial rake angle }(\gamma)-^{\circ}}^{\circ}$ & 12 & 18 & 24 \\
\hline
\end{tabular}

The response $\operatorname{Tr}$ and $R a$ can be expressed as a function of machining parameters, such as spindle speed $(N)$, feed rate $(F)$, axial depth of cut $\left(D_{a}\right)$, radial depth of cut $\left(D_{r}\right)$, and geometrical parameters such as radial rake angle $(\gamma)$

$$
\begin{aligned}
& \operatorname{Tr}=\phi\left(N, F, D_{a}, D_{r}, \gamma\right)+e u i \\
& R a=\mu\left(N, F, D_{a}, D_{r}, \gamma\right)+e u i
\end{aligned}
$$

where $\phi$ is the response surface, $e$ is the residual, $u$ is the number of observations in the factorial experiment, and $i$ represents the level of the $i^{\text {th }}$ factor in the $u^{\text {th }}$ observation. When the mathematical forms of $\phi, \mu$ are unknown, $T r$ and $R a$ can be approximated satisfactorily within the experimental region by polynomials in terms of the machining parameter variable. Central composite design methods will certainly minimize the number of experiments without reducing the accuracy [15]. 
An Integrated Approach of RSM and MOGA for

Surface Roughness in the End Milling of Al 6061-T6

Table 2 Experimental values with responses

\begin{tabular}{|c|c|c|c|c|c|c|c|c|c|}
\hline S.No & $\begin{array}{c}N \\
\mathrm{rpm}\end{array}$ & $\begin{array}{c}F \\
\mathrm{~mm} / \mathrm{rev}\end{array}$ & $\begin{array}{c}D_{r} \\
\mathrm{~mm}\end{array}$ & $\begin{array}{c}D_{a} \\
\mathrm{~mm}\end{array}$ & $\begin{array}{l}\gamma \\
\circ\end{array}$ & $\begin{array}{c}\text { Tr-exp } \\
{ }^{\circ} \mathrm{C}\end{array}$ & $\begin{array}{c}R a-\exp \\
\mu \mathrm{m}\end{array}$ & $\begin{array}{c}\text { Tr-pred } \\
{ }^{\circ} \mathrm{C}\end{array}$ & $\begin{array}{c}\text { Ra-Pred } \\
\mu \mathrm{m}\end{array}$ \\
\hline 1. & 2500 & 0.08 & 0.7 & 1 & 18 & 26 & 0.51 & 28.16 & 0.50 \\
\hline 2. & 1400 & 0.12 & 1 & 1 & 12 & 33 & 0.64 & 32.99 & 0.64 \\
\hline 3. & 3600 & 0.04 & 1 & 0.4 & 24 & 34 & 0.46 & 33.36 & 0.47 \\
\hline 4. & 2500 & 0.08 & 0.7 & 0.4 & 18 & 26 & 0.45 & 24.60 & 0.44 \\
\hline 5. & 3600 & 0.04 & 0.4 & 1 & 24 & 34 & 0.51 & 33.47 & 0.51 \\
\hline 6. & 3600 & 0.04 & 0.4 & 0.4 & 12 & 18 & 0.43 & 18.27 & 0.42 \\
\hline 7. & 3600 & 0.12 & 0.4 & 1 & 12 & 34 & 0.41 & 33.69 & 0.41 \\
\hline 8. & 2500 & 0.08 & 1 & 0.7 & 18 & 25 & 0.52 & 27.60 & 0.48 \\
\hline 9. & 2500 & 0.08 & 0.7 & 0.7 & 18 & 24 & 0.45 & 24.83 & 0.48 \\
\hline 10. & 2500 & 0.08 & 0.4 & 0.7 & 18 & 25 & 0.43 & 23.16 & 0.45 \\
\hline 11. & 1400 & 0.12 & 1 & 0.4 & 24 & 32 & 0.53 & 32.08 & 0.54 \\
\hline 12. & 1400 & 0.04 & 1 & 0.4 & 12 & 17 & 0.61 & 17.58 & 0.61 \\
\hline 13. & 1400 & 0.04 & 0.4 & 1 & 12 & 15 & 0.53 & 15.69 & 0.52 \\
\hline 14. & 1400 & 0.12 & 0.4 & 0.4 & 12 & 14 & 0.52 & 14.99 & 0.52 \\
\hline 15. & 3600 & 0.12 & 0.4 & 0.4 & 24 & 32 & 0.5 & 31.77 & 0.51 \\
\hline 16. & 2500 & 0.08 & 0.7 & 0.7 & 18 & 22 & 0.45 & 24.83 & 0.48 \\
\hline 17. & 2500 & 0.08 & 0.7 & 0.7 & 18 & 23 & 0.45 & 24.83 & 0.48 \\
\hline 18. & 3600 & 0.08 & 0.7 & 0.7 & 18 & 25 & 0.44 & 28.82 & 0.42 \\
\hline 19. & 2500 & 0.08 & 0.7 & 0.7 & 24 & 26 & 0.55 & 27.82 & 0.51 \\
\hline 20. & 1400 & 0.12 & 0.4 & 1 & 24 & 27 & 0.71 & 27.19 & 0.71 \\
\hline 21. & 1400 & 0.08 & 0.7 & 0.7 & 18 & 23 & 0.53 & 19.93 & 0.53 \\
\hline 22. & 1400 & 0.04 & 1 & 1 & 24 & 17 & 0.63 & 16.77 & 0.63 \\
\hline 23. & 2500 & 0.04 & 0.7 & 0.7 & 18 & 20 & 0.55 & 19.82 & 0.57 \\
\hline 24. & 2500 & 0.08 & 0.7 & 0.7 & 18 & 26 & 0.48 & 24.83 & 0.48 \\
\hline 25. & 1400 & 0.04 & 0.4 & 0.4 & 24 & 15 & 0.53 & 15.77 & 0.53 \\
\hline 26. & 3600 & 0.12 & 1 & 0.4 & 12 & 31 & 0.45 & 30.58 & 0.46 \\
\hline 27. & 3600 & 0.04 & 1 & 1 & 12 & 30 & 0.52 & 29.27 & 0.52 \\
\hline 28. & 3600 & 0.12 & 1 & 1 & 24 & 35 & 0.51 & 33.77 & 0.52 \\
\hline 29. & 2500 & 0.08 & 0.7 & 0.7 & 12 & 25 & 0.45 & 23.93 & 0.47 \\
\hline 30. & 2500 & 0.08 & 0.7 & 0.7 & 18 & 26 & 0.46 & 24.83 & 0.48 \\
\hline 31. & 2500 & 0.08 & 0.7 & 0.7 & 18 & 31 & 0.52 & 24.83 & 0.48 \\
\hline 32. & 2500 & 0.12 & 0.7 & 0.7 & 18 & 26 & 0.63 & 26.93 & 0.59 \\
\hline
\end{tabular}

\section{Development of Response Surface Model}

A central composite design is the most commonly used response surface designed experiment. For example, for a three-factor and one response surface experiment, the following second-order model is the standard model for CCD. [5] The quadratic polynomial developed, which gives the relation between the response surface $y$ and the process variable $\mathrm{x}$ under investigation, is given by

$$
Y=\beta 0+\beta 1 \times 1+\beta 2 \times 2+\beta 3 \times 3+\beta 11 \times 12+\beta 22 \times 22+\beta 12 \times
$$

where $\beta 0$ is the constant, $\beta 1, \beta 2, \beta 3$ are the linear term coefficients, $\beta 11, \beta 22$ are the quadratic term coefficients and $\beta 12$ is the interaction term coefficient. Regression equations were formed using the values of the polynomial coefficients.

A statistical software design expert V.10 was used to calculate the values of these coefficients. The second order mathematical model is developed using the experimental 
N. Zeelanbasha, V. Senthil, B.R. Senthil Kumar
An Integrated Approach of RSM and MOGA for the Prediction of Temperature Rise and Surface Roughness in the End Milling of Al 6061-T6

values and responses to predict the temperature rise $(T r)$ and the surface roughness $(R a)$; they are given below in equation 2 and 3 .

$T r=-32.4409+0.008742 * N+296.03 * F+30.18071 * D_{a}+11.17397 * D_{r}+0.42642 * \gamma^{\prime}-$
$0.03693 * N * F-0.00303 * N * D_{a}+0.000758 * N * D_{r}+0.0000947 * N * \gamma+41.66667 * F$
$* D_{a}+41.66667 * F^{*} D_{r^{-}} 1.5625 * F * \gamma-20.8333 * D_{a} * D_{r}-0.69444 * D_{a} * \gamma-1.11111 *$
$D_{r} * \gamma-0.000000372 * N^{2}-906.375 * F^{2}+6.108898 * D_{r}^{2}+17.22001 * D_{r}^{2}+0.029161 * \gamma^{2}$

$R a=+0.452928+0.000034 * N-9.09448 * F+0.746547 * D_{a}+0.210015 * D_{r}-0.000874 *$ $\gamma-0.000213 * N * F-0.00000568182 * N * D_{a}-0.000040 * N * D_{r}+0.000000662879 * N *$ $\gamma-1.19792 * F * D_{a}+0.572917 * F * D_{r}+0.049479 * F * \gamma+0.048611 * D_{a} * D_{r}-0.015625$ $* D_{a} * \gamma+0.008681 * D_{r} * \gamma-0.0000000946627 * N^{2}+58.46614 * F^{2}-0.238380 * D_{a}^{2}-$ $0.182824 * D_{r}{ }^{2}+0.000098 * \gamma^{2}$

\subsection{ANOVA for Temperature Rise}

In this study, ANOVA was performed at a 95\% confidence level. The significance of the model was tested using the analysis of variance (ANOVA) technique. The $F$-value of 4.63 developed by the model (shown in Tab. 3) implies that the model is significant for temperature rise. There is only a $0.61 \%$ chance that an $F$-value this large could occur due to noise. Values of Prob $>F$ of less than 0.05 indicate the significance of model terms. The Lack of Fit $F$-value of 4.33 implies that the Lack of Fit is not significant relative to the pure error. There is a $6.46 \%$ chance that a Lack of Fit F-value this large could occur due to noise. The $R^{2}$ value and the predicted $R^{2}$ value of the temperature rise are 0.91 and -3.12 , respectively. The value of coefficient of variation $(\mathrm{CV})$ is equal to $12.08 \%$.

Table 3 Adequacy of the model for $T r$

\begin{tabular}{|c|c|c|c|c|c|c|c|}
\hline Source & Sum of squares & $D F$ & Mean squares & $\begin{array}{c}F \\
\text { calculated }\end{array}$ & $\begin{array}{c}P \text {-Value } \\
\text { Prob }>F\end{array}$ & $R^{2}$ & Adequacy of the model \\
\hline Model & 1039.334 & 20 & 51.96668 & 5.463106 & 0.003025 & 0.91 & adequate \\
\hline Residual & 104.6352 & 11 & 9.512294 & & & & \\
\hline Lack of fit & 53.3019 & 6 & 8.883651 & 0.865291 & 0.574654 & & inadequate \\
\hline
\end{tabular}

\subsection{ANOVA for Surface Roughness}

ANOVA was performed at a $95 \%$ confidence level. The $F$-value of 5.88 developed by the model (shown in Tab. 4) implies that the model is significant for surface roughness. There is only a $0.22 \%$ chance that an $F$-value this large could occur due to noise. Values of Prob $>F$ of less than 0.05 indicate the significance of model terms. The Lack of Fit $F$-value of 2.33 implies that the Lack of Fit is significant relative to the pure error. There is a $22.665 \%$ chance that a Lack of Fit F-value this large could occur due to noise. The $R^{2}$ value and the predicted $R^{2}$ value of surface roughness are 0.91 and -3.05 , respectively. The value of coefficient of variation $(\mathrm{CV})$ is equal to $6.81 \%$.

Table 4 Adequacy of the model for $R a$

\begin{tabular}{|c|c|c|c|c|c|c|c|}
\hline Source & Sum of squares & $D F$ & Mean squares & $\begin{array}{c}F \\
\text { calculated }\end{array}$ & $\begin{array}{c}P \text {-Value } \\
\text { Prob }>F\end{array}$ & $R^{2}$ & Adequacy of the model \\
\hline Model & 0.142786 & 20 & 0.007139 & 5.876527 & 0.002201 & 0.86 & adequate \\
\hline Residual & 0.013364 & 11 & 0.001215 & & & & \\
\hline Lack of fit & 0.00948 & 6 & 0.00158 & 2.034424 & 0.226471 & & Inadequate \\
\hline
\end{tabular}


Surface Roughness in the End Milling of Al 6061-T6

\section{Results and Discussion}

\subsection{Response Surface Method}

\subsubsection{Interaction and direct effects of machining parameters on temperature rise}

Figure $2 \mathrm{a}$ and $3 \mathrm{a}$ depict the interaction effect and the direct effect of spindle speed on temperature rise. The figure showing the interaction effect proves that the spindle speed and the feed rate have a significant effect on the temperature rise of the milling process. Figure $2 \mathrm{a}$ illustrates the fact that the increase in spindle speed resulted in an increased temperature rise; it is minimal in the spindle speed range of 1400 to $2000 \mathrm{rpm}$. An increase in the spindle speed increases the rate at which energy is dissipated through plastic deformation and friction. Thus, the rate of heat generation in the cutting zone increases, which results in a high cutting temperature. Figures $2 b-c$ and $3 c-d$ illustrate that an increase in the axial depth of cut increases the temperature rise. Increases in axial and radial depths of cut of 0.7 to $1 \mathrm{~mm}$ cause a larger amount of workpiece material to be removed; this in turn increases the cutting temperature. The Scanning Electron Microscopy (SEM) analyses showed that at lower values of axial and radial depths of cut of $0.4-0.69 \mathrm{~mm}$, at lower spindle speeds of 1400-2000 rpm, less tool material adheres to the machined surface of workpiece than in the case of higher values of depth of cut shown in Figure 6a.
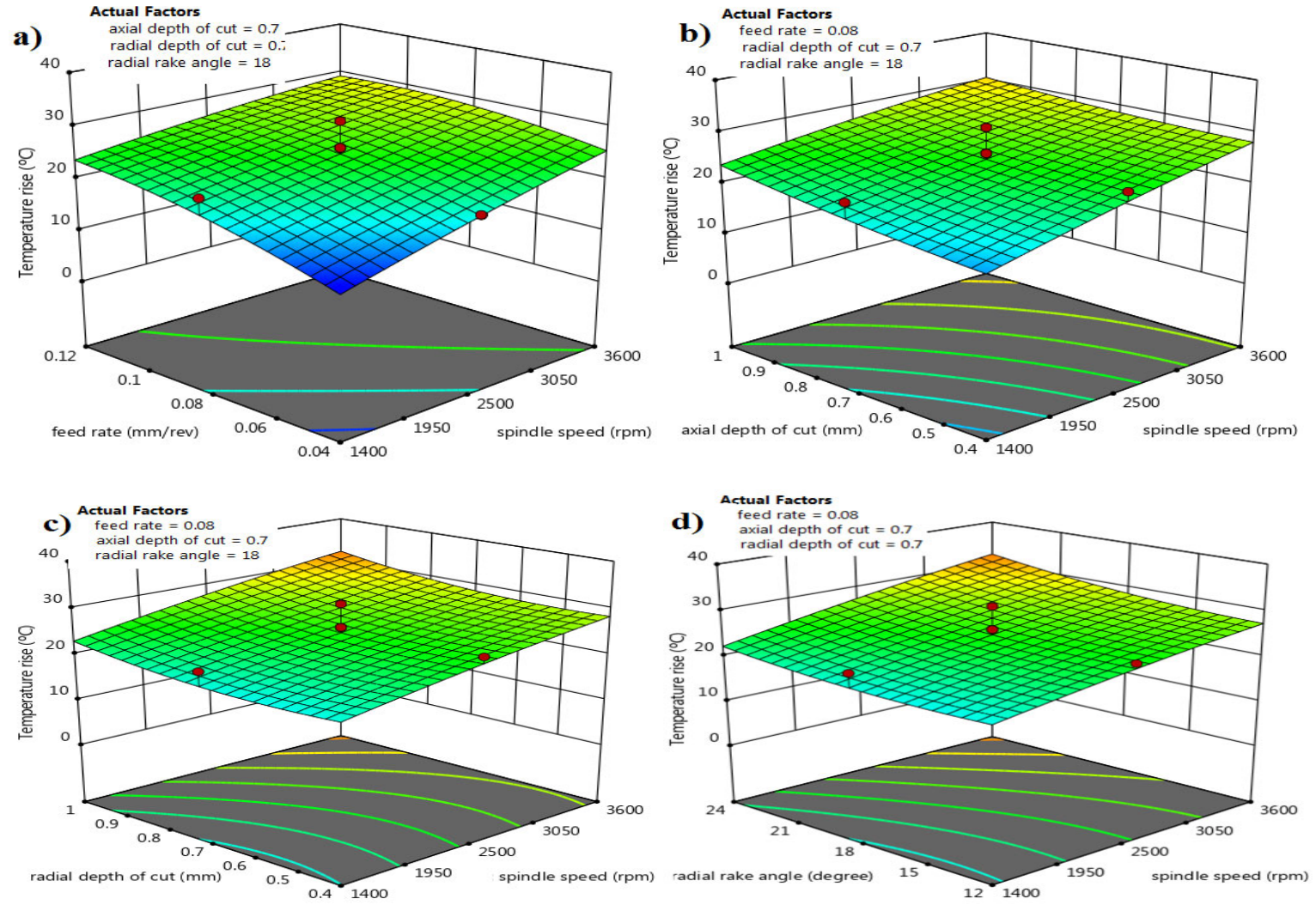

Fig. 2a-d 3D plot of machining parameters over temperature rise

This adhesion of tool material to the work piece causes poor surface finish. From Fig. $2 \mathrm{~d}$ and $3 \mathrm{e}$ one can see that the radial rake angle has a significant effect on the temperature rise of the milling process. Figure $3 \mathrm{~d}$ show that a smaller radial rake angle $\left(12^{\circ}\right.$ to $\left.15^{\circ}\right)$ would decrease the temperature rises. 
N. Zeelanbasha, V. Senthil, B.R. Senthil Kumar
An Integrated Approach of RSM and MOGA for the Prediction of Temperature Rise and Surface Roughness in the End Milling of Al 6061-T6 a)

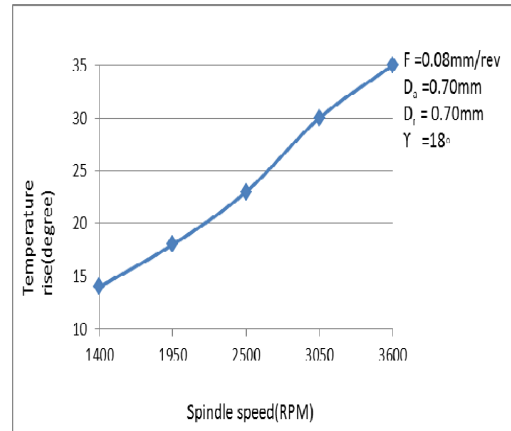

b)

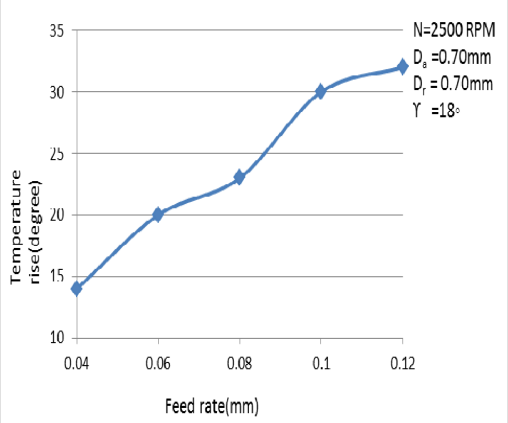

c)

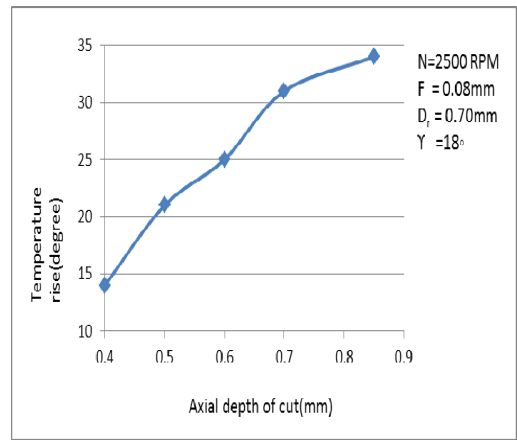

e)

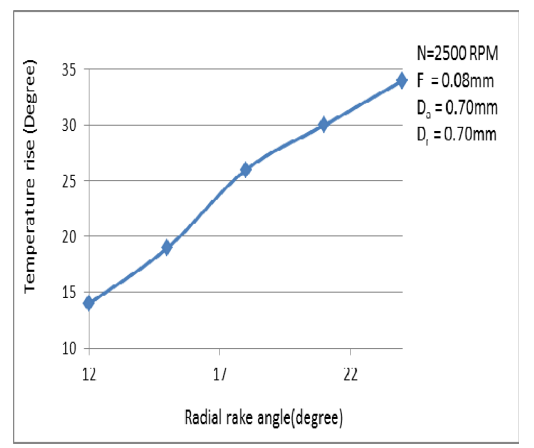

Fig. 3a-e Direct effect plots for machining parameters over temperature rise

The cutting temperature is significantly affected by the radial rake angle: the bigger the radial rake angle is, the greater the deformation and the cutting force are and more heat will be generated in chip formation. A larger radial rake angle $\left(20^{\circ}\right.$ to $\left.24^{\circ}\right)$ makes the tool sharper and more pointed; this decreases the strength of the tool and may cause the formation of a chip layer shown in the SEM in Fig. 6b. The selection of a smaller radial rake angle helps in the formation of continuous chips in ductile materials and reduces the formation of an edge. Thus the formation of continuous chips promotes better heat removal between the cutting tool and the workpiece. The heat removal intensity is predominant, leading to a reduction in the cutting temperature; the cutting temperature decreases with a decrease in the radial rake angle $\left(12^{\circ}\right.$ to $\left.16^{\circ}\right)$ of the tool. The temperature rises on the rake face of the tool affect the surface finish and the metallurgical state of the machined surface shown in the SEM in Fig.6a.

\subsubsection{Interaction and direct effects of machining parameters on surface roughness}

From Fig. 4a, it has been observed that the machining parameters have significant effects on the responses. Figure 5a-b shows that the spindle speed and the feed rate are inversely proportional with surface roughness. Surface roughness decreases with an increase in the spindle speed; better surface roughness can be achieved between 3000 and $3600 \mathrm{rpm}$. The change in the feed rate from 0.06 to $0.1 \mathrm{~mm} / \mathrm{rev}$ at a higher spindle speed reduces the surface roughness (from 0.71 to $0.4 \mu \mathrm{m}$ ). If the feed rate increases gradually from 0.051 to 0.06 $\mathrm{mm} / \mathrm{rev}$ with an increase in the spindle speed from 1400 to $2400 \mathrm{rpm}$, the surface roughness value increases proportionally. Hence, it has been concluded that the lower surface roughness $(0.4 \mu \mathrm{m})$ can be achieved if the optimum change in the feed rate is between 0.07 and 0.09 $\mathrm{mm} / \mathrm{rev}$. From Fig. 4b-c and 5c-d, it is evident that the axial and the radial depth of cut show an inverse relationship with the spindle speed. Surface roughness increases with an increase in the axial depth of cut; this is due to the fact that a higher depth of cut increases the cutting force, this makes the tool and the workpiece unstable, with a final result of increased surface roughness. The change in depth of cut from 0.4 to $0.6 \mathrm{~mm}$ at a higher spindle speed does not affect the surface roughness significantly, whereas the same change at a lower spindle speed 
produces a high torque which causes inaccurate axial loading on the machining surface; thus, the change in the depth of cut at a lower speed has a significant effect on the surface roughness. If the depth of cut increases gradually from 0.61 to $1 \mathrm{~mm}$ and the spindle speed increases from 1400 to $2500 \mathrm{rpm}$, the surface roughness value increases proportionally. Hence, it has been concluded that at a higher spindle speed, a lower depth of cut has to be preferred in order to obtain quality surface finish. From Fig. $4 \mathrm{~d}$ and $5 \mathrm{e}$, it has been observed that at the radial rake angle of $12^{\circ}$ to $13^{\circ}$, the machining process will produce good surface roughness. The radial rake angle of less than $12.5^{\circ}$ has to be preferred for good surface finish in the end milling process. The surface roughness significantly increases at radial rake angles from $14^{\circ}$ to $24^{\circ}$ at a lower spindle speed; the change in the radial rake angle from $12^{\circ}$ to $13^{\circ}$ at a lower depth of cut and a higher spindle speed does not significantly affect the surface roughness.
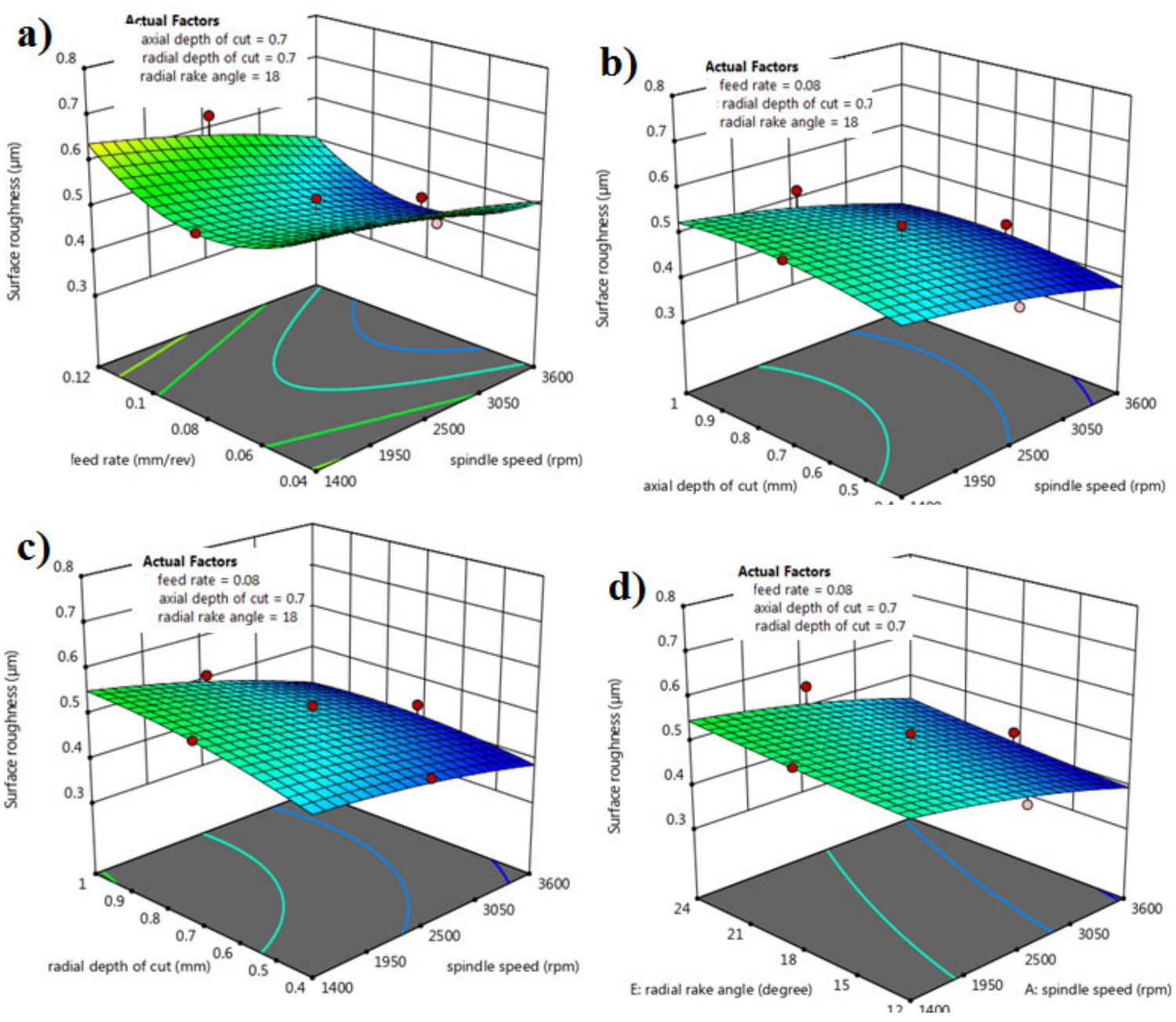

Fig. 4 3D plots of machining parameters over surface roughness

a)

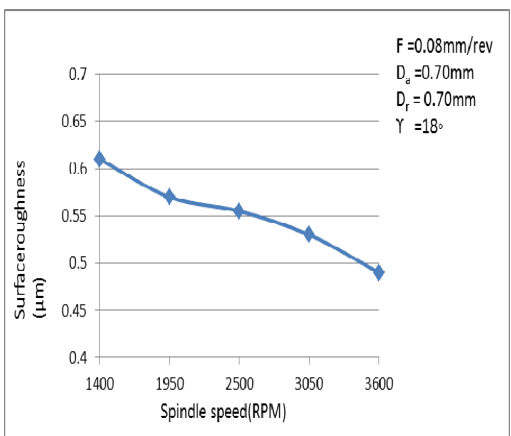

b)

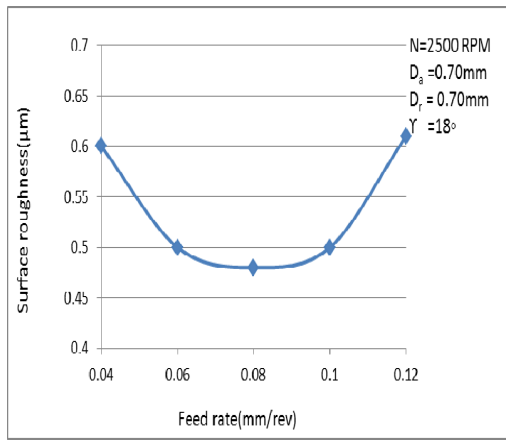

c)

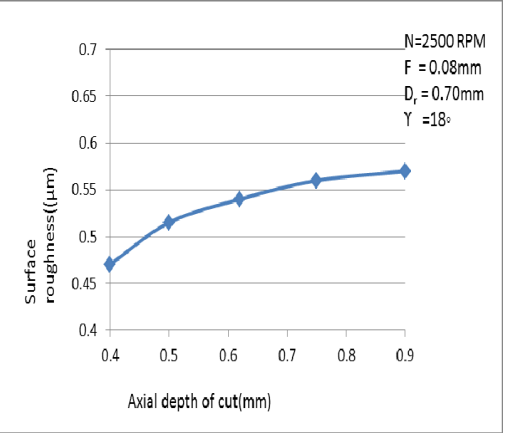


N. Zeelanbasha, V. Senthil, B.R. Senthil Kumar

d)

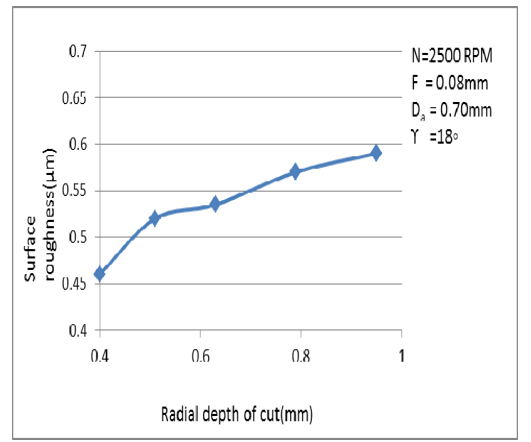

An Integrated Approach of RSM and MOGA for the Prediction of Temperature Rise and Surface Roughness in the End Milling of Al 6061-T6

e)

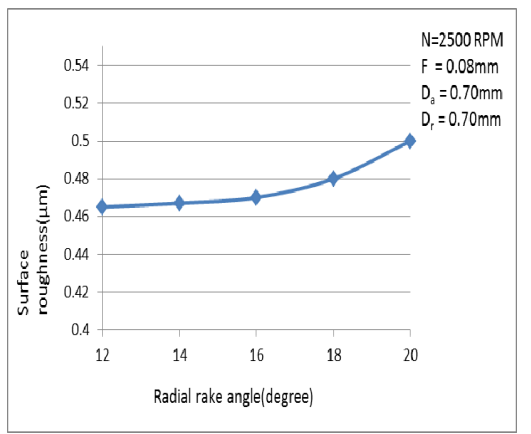

Fig. 5a-e Direct effect plots for machining parameters over surface roughness

\subsection{Surface defects}

SEM micrographs of the machined surface with a combination of different milling parameters are shown in Fig. 6. The micrographs show the main forms of surface damage in the machining of 6061-T6 aluminium: re-deposited tool material, tearing surface, feed marks, and the chip layer formation on the surface as a result of milling (Fig. 6a-d). The increase in the magnitude of the cutting force due to improper selection of machining and geometrical parameters induces a higher cutting temperature, which produces surface deformation on the machined surface and hence creates the worst surface finish.

a)

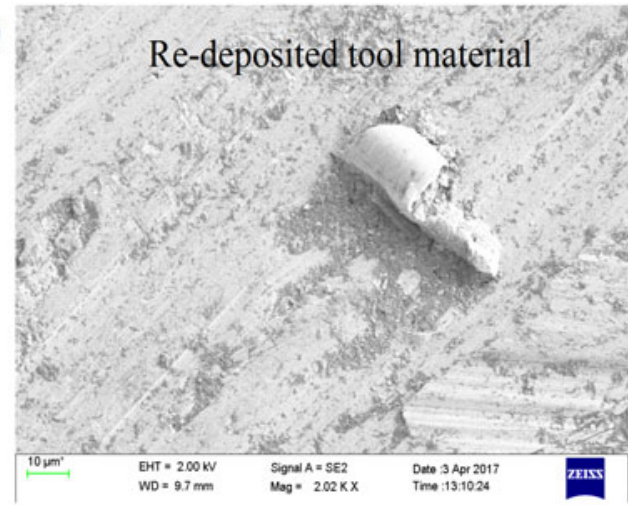

c)

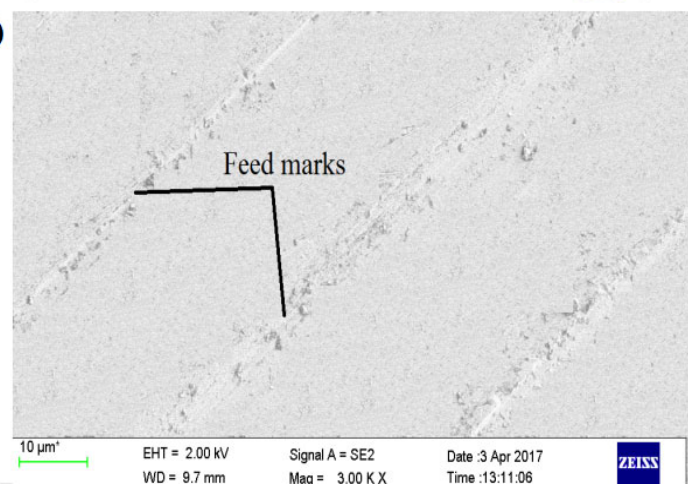

b)

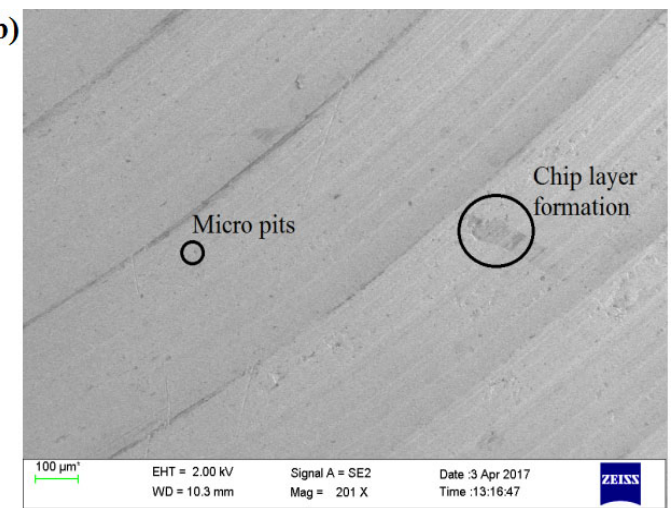

d)

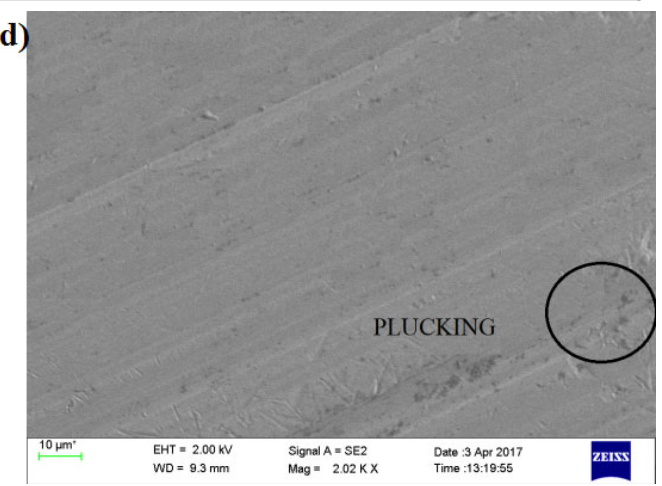

Fig. 6a-d SEM micrographs of the surface machined under different milling conditions:

(a) $N=1400 \mathrm{rpm}, F=0.12 \mathrm{~mm} / \mathrm{rev}, D_{a}=1 \mathrm{~mm}, D r=0.4 \mathrm{~mm}, \gamma=24^{\circ}$,

(b) $N=2500 \mathrm{rpm}, F=0.08 \mathrm{~mm} / \mathrm{rev}, D_{a}=0.7 \mathrm{~mm}, D r=0.7 \mathrm{~mm}, \gamma=24^{\circ}$

(c) $N=2500 \mathrm{rpm}, F=0.12 \mathrm{~mm} / \mathrm{rev}, D_{a}=0.7 \mathrm{~mm}, D_{r}=0.7 \mathrm{~mm}, \gamma=18^{\circ}$

(d) $N=1400 \mathrm{rpm}, F=0.04 \mathrm{~mm} / \mathrm{rev}, D_{a}=1 \mathrm{~mm}, D_{r}=1 \mathrm{~mm}, \gamma=24^{\circ}$

It was observed that a higher range of spindle speed (2400 to $3600 \mathrm{rpm}$ ) causes the cutting temperature to rise during the machining process; the higher cutting temperature causes the tool to soften. Those were the main reasons for the cutting tool inclusion in the 
surface texture. The cutting tool inclusion in the workpiece material would produce poor surface texture and burrs on the machined surface shown in Fig.6a. Feed mark defects occur due to the combination of spindle speed and feed direction in the tool motion during milling. Figure $6 \mathrm{c}$ indicates that the major feed mark occurs due to the large values of feed mark. In the surface micrographs one can note a small amount of plucking on the machined surface at high axial and radial depths of cut. In Fig. $6 \mathrm{~d}$ one can note a large number of scratches on the machined surface at an axial depth of cut of $1 \mathrm{~mm}$.

\subsection{Multi objective genetic algorithm (MOGA)}

In this study, MOGA has been employed for multi objective optimization with parameter limits. A second order mathematical model has been developed to observe the optimal relationship between the machining parameters, such as spindle speed, feed rate, axial and radial depths of cut, and radial rake angle, and the responses, such as temperature rise and surface roughness. This function was input into the GA Toolbox of MATLAB 2010a as the objective function

Find: $N, F, D_{a}, D_{r}, \gamma$

To minimize: $T r, R a$

Subjected to constraints: $T r \leq T r$ limit, $R a \leq R a$ limit

Within parameter ranges:

$$
\begin{aligned}
& 1500 \leq N \leq 3500 \mathrm{rpm} \\
& 0.02 \leq F \leq 0.06 \mathrm{~mm} / \mathrm{rev} \\
& 0.4 \leq D_{\mathrm{a}} \leq 1 \mathrm{~mm} \\
& 0.4 \leq D_{\mathrm{r}} \leq 1 \mathrm{~mm} \\
& 12 \leq \gamma \leq 24^{\circ}
\end{aligned}
$$

where $\operatorname{Tr}$ limit and $R a$ limit indicate the lower and upper limits that need to be satisfied for responses. The critical parameters in MOGA are: selected population size of 100, mutation rate of 0.1 , crossover fraction of 0.8 , generation of 1000 , and population fraction of 0.35 .

Fig.7 shows the Pareto optimal frontier distributed points generated from the optimization of responses. The parameter combinations of eighteen sets of non-dominated Pareto optimal solutions are presented in Tab. 5. From the investigation, it has been observed that all the solutions generated from MOGA are equally good. It should be noted that the choice of a selection of Pareto optimal solutions depends mostly upon the process engineer's expectation and manufacturer requirements.

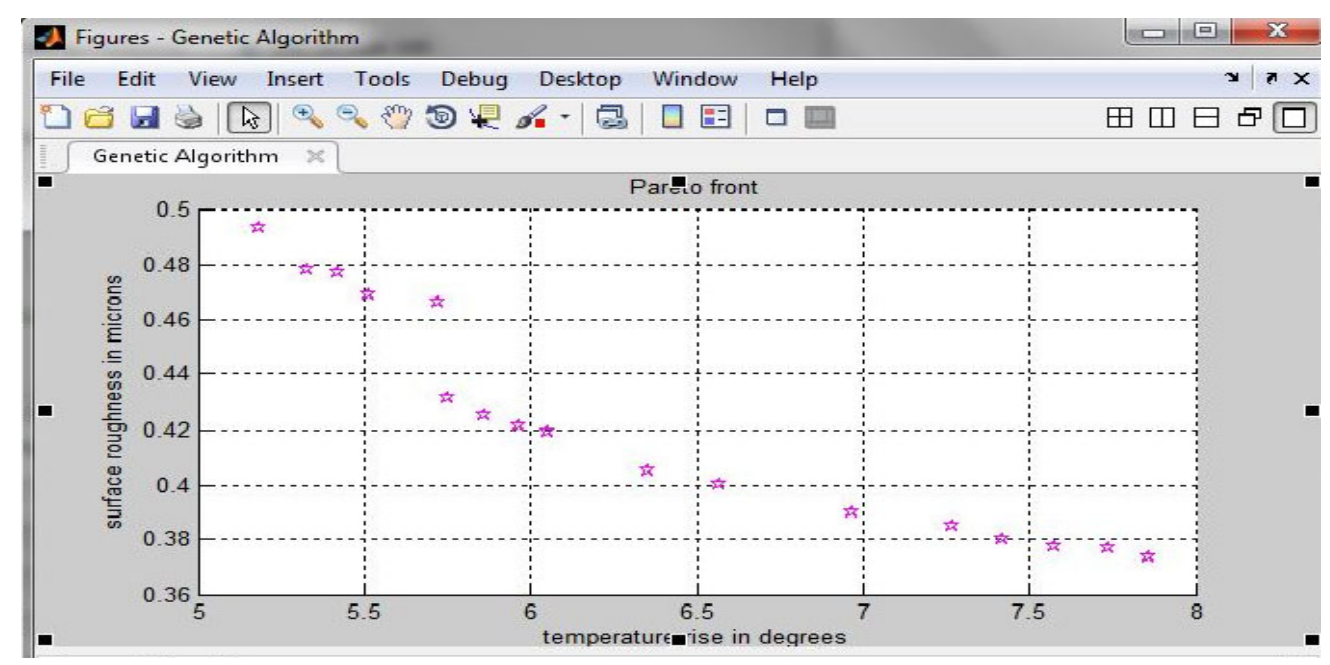

Fig. 7 Pareto-optimal frontier chart 
N. Zeelanbasha, V. Senthil, B.R. Senthil Kumar
An Integrated Approach of RSM and MOGA for the Prediction of Temperature Rise and Surface Roughness in the End Milling of Al 6061-T6

Table 5 Pareto-optimal solutions

\begin{tabular}{|c|c|c|c|c|c|c|}
\hline$N / \mathrm{rpm}$ & $F / \mathrm{mm} / \mathrm{rev}$ & $D_{r} / \mathrm{mm}$ & $D_{a} / \mathrm{mm}$ & $\gamma /{ }^{\circ}$ & Tr-Pred $/{ }^{\circ} \mathrm{C}$ & Ra-Pred $/ \mu \mathrm{m}$ \\
\hline 1740.566 & 0.068 & 0.418 & 0.412 & 12.396 & 12.747 & 0.417 \\
\hline 1691.598 & 0.045 & 0.422 & 0.415 & 12.403 & 9.131 & 0.479 \\
\hline $\mathbf{3 2 7 4 . 7 4 1}$ & $\mathbf{0 . 0 7 9}$ & $\mathbf{0 . 4 0 5}$ & $\mathbf{0 . 9 3 0}$ & $\mathbf{1 2 . 2 8 0}$ & $\mathbf{2 9 . 5 1 6}$ & $\mathbf{0 . 3 4 7}$ \\
\hline 3274.741 & 0.079 & 0.405 & 0.993 & 12.280 & 31.266 & 0.341 \\
\hline 2409.863 & 0.073 & 0.407 & 0.406 & 12.378 & 16.287 & 0.388 \\
\hline 2993.473 & 0.077 & 0.407 & 0.410 & 12.279 & 19.036 & 0.360 \\
\hline $\mathbf{3 2 7 3 . 7 0 0}$ & $\mathbf{0 . 0 7 8}$ & $\mathbf{0 . 4 0 5}$ & $\mathbf{0 . 4 4 0}$ & $\mathbf{1 2 . 2 6 3}$ & $\mathbf{2 0 . 3 9 4}$ & $\mathbf{0 . 3 4 7}$ \\
\hline 3135.322 & 0.074 & 0.407 & 0.445 & 12.357 & 19.796 & 0.358 \\
\hline 1865.770 & 0.054 & 0.417 & 0.422 & 12.421 & 11.666 & 0.442 \\
\hline 2628.220 & 0.074 & 0.405 & 0.412 & 12.362 & 17.361 & 0.378 \\
\hline 1690.819 & 0.044 & 0.422 & 0.423 & 12.347 & 9.121 & 0.481 \\
\hline $\mathbf{1 6 9 7 . 5 1 5}$ & $\mathbf{0 . 0 4 9}$ & $\mathbf{0 . 4 2 0}$ & $\mathbf{0 . 4 1 8}$ & $\mathbf{1 2 . 5 7 3}$ & $\mathbf{9 . 9 6 9}$ & $\mathbf{0 . 4 6 3}$ \\
\hline 2869.979 & 0.073 & 0.407 & 0.410 & 12.349 & 18.287 & 0.369 \\
\hline 1694.938 & 0.054 & 0.419 & 0.414 & 12.403 & 10.594 & 0.447 \\
\hline 2087.900 & 0.070 & 0.409 & 0.444 & 12.386 & 14.880 & 0.407 \\
\hline 1819.763 & 0.060 & 0.422 & 0.477 & 12.415 & 12.719 & 0.438 \\
\hline 1925.908 & 0.065 & 0.413 & 0.419 & 12.404 & 13.334 & 0.416 \\
\hline 1700.943 & 0.057 & 0.420 & 0.432 & 12.539 & 11.225 & 0.443 \\
\hline
\end{tabular}

\subsection{Verification experiment for optimization}

Three sets of predicted Pareto-optimal solutions are considered for verification. From the comparison between the predicted and actual solutions, it has been observed that the percentage of error lies between 1.5 to $2 \%$, which shows the validity of the model. The predicted Pareto optimal solutions shown in bold type in Tab. 5 were validated, and it was found that the percentage of error is within $\pm 2 \%$. The experiment results show good agreement with predicted responses, such as $T r$ and $R a$, and optimum machining parameters such as $N, F, D_{a}, D_{r}, \gamma$.

\section{Conclusion}

The experiments were performed on Al 6061-T6 to measure temperature rise $(\mathrm{Tr})$ and surface roughness $(R a)$. Statistical models have been developed for responses using the central composite design with three level factors. The second order mathematical models developed are used to determine the optimum machining parameters in order to achieve minimum $T r$ and $R a$. Analysis of variance was used to study the effects of machining parameters on the responses. Response surface-based MOGA was used to predict and optimize the machining parameters and responses. From this investigation into the interaction effect and direct effect surface plots, the following conclusions have been drawn:

- The key forms of surface defect in the end milling of Al 6061-T6 are feed marks, scratch marks, adhered material particles, tearing surface, and chip layer formation. The usual feed marks in end milling are intermediate similar lines. The aggressive feed marks can be reduced by selecting lower feed rate values.

- Re-deposited tool material and burrs are confirmed to appear at the low spindle speed condition, while tearing surfaces and scratches occur at the larger value of axial and radial depths of cut condition. The formation of plucking confirms the major influence of radial rake angle on the cutting tool.

- In the analysis of temperature rise $(\operatorname{Tr})$, it was found that the minimum $\operatorname{Tr}$ can be achieved at minimal spindle speed (1400 to 2000) rpm, feed rate of less than $0.05 \mathrm{~mm} / \mathrm{rev}$, axial and radial depths of cut of less than $0.6 \mathrm{~mm}$ and radial rake angle of $12^{\circ}$ to $13^{\circ}$. 
Surface Roughness in the End Milling of Al 6061-T6

- In the analysis of surface roughness $(R a)$, it was found that the minimum surface roughness can be achieved at spindle speeds of 3000-3600 rpm, feed rate of 0.04 to $0.06 \mathrm{~mm} / \mathrm{rev}$, axial and radial depths of cut of less than $0.6 \mathrm{~mm}$, and radial rake angle of less than $12.5^{\circ}$

- Based on multi objective optimization by non-dominated sorted genetic algorithm, the parameter combination of eighteen sets of non-dominated Pareto optimal solutions are obtained; it has been determined that all the solutions generated from MOGA are equally good.

- It should be noted that the choice of Pareto optimal solutions entirely depends upon the manufacturer and the process engineer expectations, and requirements.

\section{Nomenclature}

$N=$ Spindle speed (rpm)

$F=$ Feed rate $(\mathrm{mm} / \mathrm{rev})$

$D a=$ Axial depth of cut (mm)

$D r=$ Radial depth of cut (mm)

$\gamma=$ Radial rake angle $\left(^{\circ}\right)$
$T r=$ Temperature rise $\left({ }^{\circ} \mathrm{C}\right)$

$R \mathrm{a}=$ Surface roughness $(\mu \mathrm{m})$

$D F=$ Degree of freedom

Exp=experimental

Pred $=$ prediction

\section{REFERENCES}

[1] Palanisamy, P.; Rajendran, I.; Shanmugasundaram, S.; Saravanan, R. Prediction of cutting forcer and temperature rise in endmilling Operatio// Proc Inst Mech Eng B J Eng Manuf. 220 (10), (2008), pp. 1577-1587, https://doi.org/10.1243/09544054JEM542

[2] Naohiko Sugita, Keigo Ishii, Tatsuo Furusho, Kanako Harada, Mamoru Mitsuishi. Cutting temperature measurement by a micro-sensor array integrated on the rake face of a cutting tool// CIRP Annals Manufacturing Technology, 64, (2015), pp, 77-80.

[3] Leshock, CE.; Shin, YC. Investigation of cutting temperature in turning by a tool-work thermocouple technique// ASME J Manuf Sci Eng 119, (1997), pp.502-508. https://doi.org/10.1115/1.2831180

[4] El Hakim, M.A.; Shalaby, M.A.; b.; Veldhuis, S.C; Dosbaeva, G.K.; Effect of secondary hardening on cutting forces, cutting temperature, and tool wear in hard turning of high alloy tool steels// Measurement, 65, (2015), pp, 233-238. https://doi.org/10.1016/j.measurement.2014.12.033

[5] Yong Feng, Lei Zheng, Mulan Wang, Baosheng Wang, Junming Hou, Tiejun Yuan. Research on cutting temperature of work-piece in milling process based on WPSO// Int J Adv Manuf Technol, 128, (2015), pp, 416-424. https://doi.org/10.1007/s00170-015-6808-9

[6] Smart, EF.; Trent, EM. Temperature distributions in tools used for cutting iron, titanium and nickel// Int J Prod Res 13, (1975), pp.265-290. https://doi.org/10.1080/00207547508942996

[7] Ali Yildiz, R. Cuckoo search algorithm for the selection of optimal machining parameters in milling operations// Int J Adv Manuf Techno, 64, (2013), pp, 55-61. https://doi.org/10.1007/s00170-012-4013-7

[8] Bharathi Raja, S.; Baska, N. Application of Particle Swarm Optimization technique for achieving desired milled surface roughness in minimum machining time// Expert Systems with Applications, 39, (2012), pp, 5982-5989.

[9] Abdalla Alrashdan.; Omar Bataineh.; Mohammad Shboo. Multi-criteria end milling parameters optimization of AISI D2 steel using genetic algorithm// Int J Adv Manuf Technol, 73, (2014), pp. 12011212. https://doi.org/10.1007/s00170-014-5921-5

[10] Ahilana, C.; Somasundaram Kumanan. Modeling and prediction of machining quality in CNC turning process using intelligent hybrid decision making tools// Applied Soft Computing, 13, (2013), pp, 1543 1551.

[11] Santos, Jr.M.C.; Machado, A.R.; Barrozo, M.A.S.; Jackson, M.J. Ezugwu, E.O. Multi-objective optimization of cutting conditions when turning aluminum alloys using genetic algorithm// Int J Adv Manuf Technol, 76, (2014), pp. 1123-1138. https://doi.org/10.1007/s00170-014-6314-5

[12] Sivasankar, M.; Jeyapaul. Modelling of An Artificial Neural Network for Electrical Discharge Machining of Hot Pressed Zirconium Diboride-Silicon Carbide Composites // Transactions of Famena, Xl-3 (2016), pp.67-80. https://doi.org/10.21278/TOF.40306 
N. Zeelanbasha, V. Senthil,

B.R. Senthil Kumar
An Integrated Approach of RSM and MOGA for the Prediction of Temperature Rise and

Surface Roughness in the End Milling of Al 6061-T6

[13] Mahesh, G.; Muthu, S.; Devadasan,S.R. Prediction of surface roughness of end milling operation using genetic algorithm// Int J Adv Manuf Technol, 77, (2015), pp, 369-381.

https://doi.org/10.1007/s00170-014-6425-z

[14] Turgay Kivak. Optimization of surface roughness and flank wear using the Taguchi method in milling of Hadfield steel with PVD and CVD coated inserts// Measurement, 50, (2014), pp, 19-28. https://doi.org/10.1016/j.measurement.2013.12.017

[15] Thanongsak Thepsonthi, Tuğrul Özel. Multi-objective process optimization for micro-end milling of Ti6Al-4V titanium alloy// Int J Adv Manuf Technol, 63, (2012), pp, 903-914. https://doi.org/10.1007/s00170-012-3980-z

[16] Venkata Rao, K.; Murthy, P.B.G.S.N. Modeling and optimization of tool vibration and surface roughness in boring of steel using RSM, ANN and SVM// J Intell Manuf, 27, 2(2016), pp, 1-11. https://doi.org/10.1007/s10845-016-1197-y.

[17] Kondayya, D.;Gopala Krishna, A. An integrated evolutionary approach for modelling and optimisation of $\mathrm{CNC}$ end milling process// International Journal of Computer Integrated Manufacturing, 25, 11(2012), pp. 1069-1084. https://doi.org/10.1080/0951192x.2012.684718

[18] Senthilkumar1, B.; Kannan, T.; Madesh, R. Optimization of flux cored arc welding process parameters by using genetic algorithm// Int J Adv Manuf Technol, 128, (2015), pp, 416-424 https://doi.org/10.1007/s00170-015-7636-7

[19] Yuvaraj, N.; Pradeep Kumara, M. Multi response Optimization of Abrasive Water Jet Cutting Process Parameters Using TOPSIS Approach// Materials and Manufacturing Processes, 38, 5(2015), pp, 205-128.

[20] Abdullah Konak, David W.; Coit, Alice E.; Smith. Multi-objective optimization using genetic algorithms: A tutorial. Reliability Engineering and System Safety, 91,(2006), pp, 9921007.

[21] Ramon Quiza Sardinas, Marcelino Rivas Santana, Eleno Alfonso Brindis, "Genetic algorithm-based multi-objective optimization of cutting parameters in turning processes// Engineering Applications of Artificial Intelligence, 19, (2006), pp, 127-133.

[22] Jun LiXiaoyong Yang, Chengzu Ren, Guang Chen, Yan Wang. Multiobjective optimization of cutting parameters in Ti-6Al-4V milling process using nondominated sorting genetic algorithm-II// Int J Adv Manuf Technol, 76, (2015), pp, 941-953. https://doi.org/10.1007/s00170-014-6311-8

[23] Rahul Dhabalea, VijayKumar, S.; Jattib, Singhc, T.P.; “ Multi-Objective Optimization of Turning Process during Machining of AlMg1SiCu Using Non-Dominated Sorted Genetic Algorithm// Procedia Materials Science 6, (2014), pp, 961-966.

[24] Sivasakthivel, PS.; Velmurugan, V.; Sudhakaran, R. Prediction of vibration amplitude from machining parameters by response surface methodology in end milling// Int J Adv Manuf Technol, 53, (5-8)(2011), pp, 453-461. https://doi.org/10.1007/s00170-010-2872-3

Submitted: $\quad 25.01 .2017$

Accepted: $\quad 05.01 .2018$
Noor basha Zeelanbasha

(Corresponding author)

Department of Mechanical Engineering

Coimbatore Institute of Technology

Coimbatore, Tamilnadu, 641014 India

E-mail:zeelu6@gmail.com

Dr. Vellimalai Senthil, Associate Professor Department of Mechanical Engineering Coimbatore Institute of Technology Coimbatore, Tamilnadu, 641014 India E-mail:vsenthil.me.cit@gmail.com

Dr. Bella Raman Senthil Kumar, Professor Department of Mechanical Engineering Nehru Institute of Engineering and Technology, Coimbatore, Tamilnadu, 641105 India

E-mail:senthilramanseetha60@gmail.com 